\title{
Contribution of Ecosystem Services to Achievement of the Sustainable Development Goals ${ }^{\dagger}$
}

\author{
Kristina Veidemane \\ Baltic Environmental Forum, Riga, Latvia; kristina.veidemane@bef.lv \\ † Presented at TERRAenVISION 2019, Barcelona, 2-7 September, 2019. \\ Published: 6 November 2019
}

\begin{abstract}
The sustainable development goals (SDGs) for 2030 are established to address global challenges including environment and human well-being. The SDGs are interconnected and achievement of them requires consideration of the planet's ecosystems and resources - land, water and air. Ecosystem services (ES) approach has a high potential for better planning, policy and decision making. Understanding how different ecosystems (e.g., forests, rivers, wetlands, grasslands) contribute to the social and economic benefits is critical to ensure the long-term biodiversity protection and sustainable use of ecosystems. A conceptual framework linking biodiversity and ecosystem condition (its structure and functions), and ES to human well-being has been well-established in EU by so called MAES process (Mapping and Assessment of Ecosystem Services) lead by the European Commission. The framework is applied in recent research studies and projects, as well as national MAES processes. Various methods are applied for MAES in terms to determine biophysical, economic and social values and to deliver integrated ecosystem assessment. Assessment of ES and trade off analysis shall provide a new perspective for land use planning and decision making at different administrative and spatial levels and in different sectoral policies. EU and national policies for instance on agriculture, fishery, forestry, climate should account the benefits provided by relevant ecosystems and to ensure that the values are not diminished but rather enhanced during the implementation of the policies. Terrestrial and water ecosystems are interconnected as land-based human activities creates pressure that impacts the conditions in water ecosystems and thus delivery of ES by rivers and lakes. For example, intensive agricultural land use produces food for people and income; however, the activity also most frequently causes problems with water quality and quantity in the catchment area and a loss of biodiversity. A risk of such trade-off shall be handled in policy development. Ecosystems also contributes to the resilience of communities by reducing the risk of natural hazards and mitigate adverse impacts. Regulating services such as flood control are substituting investments in flood protection ensured by forests, wetlands and grasslands instead of human built infrastructure. Appropriate land cover and land use shall serve as a basic flood protection measure. Natural processes are increasingly recognised to create new-type solutions that use and deploy the properties of natural ecosystems and their services in an "engineered" way. A wide range of measures called also as nature-based solutions provide another opportunity to work with nature towards global sustainability.
\end{abstract}

Keywords: sustainable development goals; ecosystem services; water ecosystems; flood risk management 
Acknowledgment: COST Action No. CA16209 "Natural Flood Retention on Private Land-LAND4FLOOD" and Interreg V-A Latvia-Lithuania Programme 2014-2020, LLI-291 “Enhancement of Green Infrastructure in the Landscape of Lowland Rivers-ENGRAVE".

(C) 2019 by the authors. Licensee MDPI, Basel, Switzerland. This article is an open access article distributed under the terms and conditions of the Creative Commons Attribution (CC BY) license (http://creativecommons.org/licenses/by/4.0/). 